\title{
Interactive comment on "On the scaling of wind turbine rotors" by Helena Canet et al.
}

\section{Anonymous Referee \#2}

Received and published: 31 August 2020

\section{General Comments:}

This paper is quite well written and covers a wide spectrum of scaling effects to be considered when conducting experiments on scaled turbines. A particular strength of the work is in examining the scaling of a very large rotor to several sizes, from near-utility to wind-tunnel. This reviewer has a few specific and technical comments to improve the paper.

Specific Comments:

Page 10, line 2: While stiffness can be changed to some extent through material substitutions and laminate sizing, and non-structural mass can be added, the effects are seen in both flap and edge directions, so some trade-off will likely need to be made depending on the scaled phenomena and modes in question. The author could elaborate on this issue as it would likely be critical to scaling aero-elastic instabilities, for 
instance.

Page 16, Table 7: For scaled turbines, the tower height and stiffness is fixed. This WESD influences the dynamics of the rotor system. How does the scaling of the rotor take this into account?

Page 21, line 10: Fatigue is mentioned here, but without data to evaluate the claim.

Interactive Also, material strength is not discussed as a limitation. This seems unlikely to be true. The operational loads of the turbine can be modified to some extent by the controller, but there are still parked loads that are quite high. This would be a very practical issue with a scaled rotor in a field environment.

Technical Comments: Page 18, line 8: Perhaps "issues", "difficulties" or "challenges" is a better word choice than "aspects"

Interactive comment on Wind Energ. Sci. Discuss., https://doi.org/10.5194/wes-2020-66, 2020. 